\title{
Optical packet switching without packet alignment
}

\author{
Hansen, Peter Bukhave; Danielsen, Søren Lykke; Stubkjær, Kristian
}

Published in:

Proceedings of the 24th European Conference on Optical Communication

Link to article, DOI:

10.1109/ECOC.1998.732737

Publication date:

1998

Document Version

Publisher's PDF, also known as Version of record

Link back to DTU Orbit

Citation (APA):

Hansen, P. B., Danielsen, S. L., \& Stubkjær, K. (1998). Optical packet switching without packet alignment. In Proceedings of the 24th European Conference on Optical Communication (Vol. Volume 1). IEEE. https://doi.org/10.1109/ECOC.1998.732737

\section{General rights}

Copyright and moral rights for the publications made accessible in the public portal are retained by the authors and/or other copyright owners and it is a condition of accessing publications that users recognise and abide by the legal requirements associated with these rights.

- Users may download and print one copy of any publication from the public portal for the purpose of private study or research.

- You may not further distribute the material or use it for any profit-making activity or commercial gain

- You may freely distribute the URL identifying the publication in the public portal 


\title{
OPTICAL PACKET SWITCHING WITHOUT PACKET ALIGNMENT
}

\author{
P.B. Hansen, S.L. Danielsen and K.E. Stubkjaer
}

Center for Broadband Telecommunications, Department of Electromagnetic Systems

Technical University of Denmark,

Building 348, DK-2800 Lyngby, Denmark

telephone: +4545253800 , telefax: +4545931634

e-mail: pbh@emi.dtu.dk

Abstract: Operation without packet alignment of an all-optical packet switch is proposed and predicted feasible through a detailed traffic analysis. Packet alignment units are eliminated resulting in a simple switch architecture while optimal traffic performance is maintained through the flexibility provided by WDM.

\section{Introduction}

Wavelength division multiplexing (WDM) has been proposed for increasing the capacity in optical networks [1]. Furthermore, an optical packet layer is considered to increase the flexibility and switching granularity of the overall network [2]. So far the approaches to optical packet switching have relied on synchronous operation of switch blocks with packet alignment at the input in analogy with an electronic packet switch. However, in contrast to the electrical domain the major advantage for photonic networking is the easy handling of large bandwidths rather than signal processing on bit level. Furthermore, since optical switch architectures are restricted to packet alignment in order to simplify the electrical management it is of great interest to assess the performance of an asynchronous (unaligned) optical packet switch block.

In this paper, it is shown that asynchronous operation leads to an increased packet loss ratio which, however, can be counteracted by using the wavelength domain for contention resolution. Thereby, a good traffic performance is attained while the use of packet alignment units is avoided.

Synchronous vs. asynchronous packet switching

Fig. 1: Optical broadcast and select $4 \times 4$ WDM packet switch which can be operated without packet alignment units. The subdivision used in the traffic analysis is shown to the left together with the packets arriving unaligned.

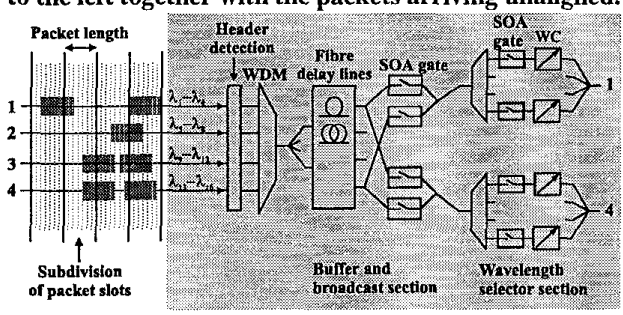

An example of an optical packet switch block without packet alignment is shown in figure 1. It is an expanded WDM version of the broadcast and select switch proposed in the European project KEOPS, which relies on header detection and alignment of incoming packets. Regarding the optical parts of such a switch block nothing is generically synchronous: the gates and the converters can be controlled with a variable offset to an internal clock, the buffering by fibre delay lines is passive and so are the remaining multi- plexers, splitters and waveguides. So, a complex optical packet alignment can be eliminated and instead each packet will be time tagged relatively to a local clock by the electrical switch management. Hereby, gates and converters can be controlled through a look-up table to accommodate to the asynchronous operation.

\section{Traffic simulation model}

To assess the traffic performance of an asynchronous switch two models have been developed. Firstly, a synchronous model based on analytical expressions were implemented following [3]. Secondly, for an asynchronous packet switch analytical terms are not available and, therefore, a computer simulation model has been developed. This is based on a subdivision of each time slot (see figure 1) and thereby allowing for randomly arriving packets.

Fig. 2: Packet loss ratio for a $4 \times 4$ switch block with a load of $0.8 \mathrm{pr}$. wavelength as a function of the number of fibre delay lines for both synchronous and asynchronous operation.

A large reduction in packet loss ratio is observed using WDM.

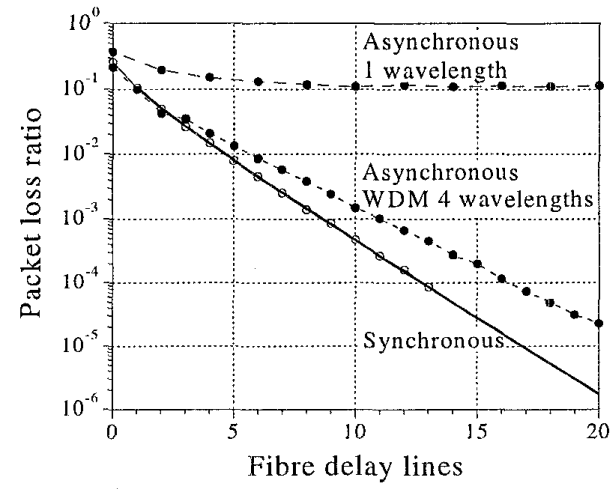

Furt hermore, the model accounts for the use of WDM since a buffer constructed from fibre delay lines in combination with wavelength converters is very flexible. The buffer is then efficiently controlled so that packets experience minimum time delay. It is noted that this can violate the packet sequence integrity, however, the probability for this is very low and therefore it has only negligible influence on the overall traffic performance [4]. 


\section{Results}

The simulation model is verified in figure 2 for the synchronous case by comparison of the packet loss ratio (PLR) from the simulations (open circles) and calculated by use of the analytical model (solid lines).

Essential aspects concerning an asynchronously operating packet switched network is illustrated in figure 2 . The figure shows the PLR for a $4 \times 4$ switch block with a load of $0.8 \mathrm{pr}$. wavelength as a function of the number of fibre delay lines. Firstly, a significant increase in the PLR is observed when an asynchronous operation scheme is used and a floor of $\sim 10^{-1}$ is observed. However, if 4 wavelengths are used on each in- and outlet the buffer becomes more flexible while the throughput is increased to a total of $4 \times 0.8 \mathrm{pr}$. inlet. Hereby, the impairment of the asynchronous operation is almost eliminated so that, e.g., for 12 fibre delay lines the PLR is only increased from $2 \cdot 10^{-4}$ to $7 \cdot 10^{-4}$.

The impairment due to the asynchronous operation originates from the fact that the buffering is not as efficient as in the synchronous case. If the packets arrive in a synchronous manner the buffer capacity will be used optimally and there will be no wasted space in the buffer. On the contrary, packets with random arrival time will result in generation of an excess load as depicted in figure 3 . For multiple wavelengths pr. inlet the packets can be assigned the wavelength that will result in the smallest amount of excess load and thereby yielding a more flexible and efficient buffer.

Fig. 3: Excess load arises when packets enter the optical buffer with random arrival time.

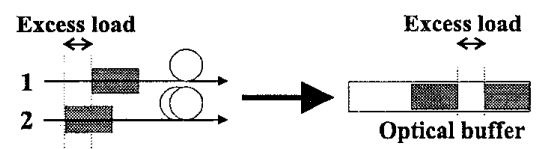

In figure 4 both the excess load and the total load out of the buffer, i.e., data and unusable buffer space, are shown as a function of the number of fibre delay lines for a $4 \times 4$ switch block with a load of $0.8 \mathrm{pr}$. wavelength. The excess load increases asymptotically to $\sim 0.3$ which together with the input load of 0.8 result in the total load of $>1$, which means that packets are lost and that the total output load saturates at $\sim 1$. Evidently, with a buffer output load of $\sim 1$ the PLR will exhibit a floor as seen in figure 2 .

Fig. 4: The buffer output load (top) and the load of the empty data stored (bottom) as a function of the number of fibre delay lines for a $4 \times 4$ switch block with a input load of 0.8 with 1 and 4 wavelengths, respectively.

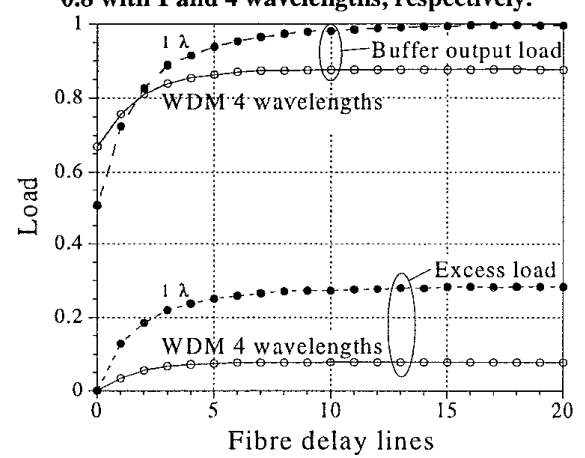

Fig. 5: The packet loss ratio as a function of the load for a $4 \times 4$ switch block with 8 fibre delay lines and the number of wavelengths as a parameter.

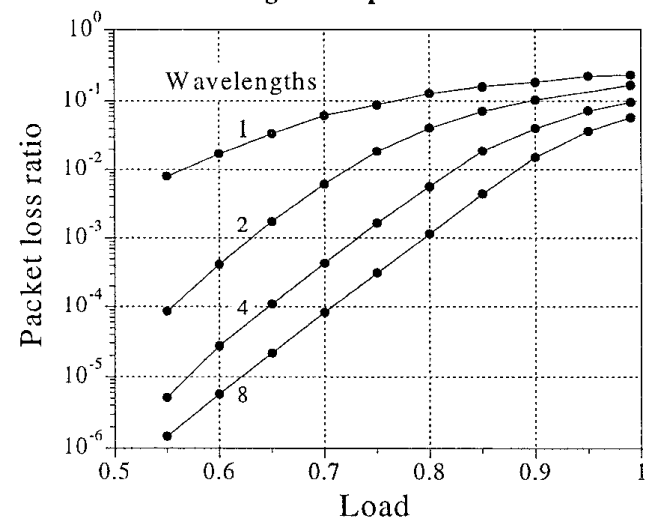

It is essential to note that the generation of an excess load can not be counteracted by increasing the number of fibre delay lines but only by making the buffer more flexible. The excess load will, therefore, be reduced when using multiple wavelengths. This can be observed in figure 3 where the excess load is reduced to only $\sim 0.1$ and the total output load consequently saturates at $\sim 0.9$. In turn, this results in the improved performance shown in figure 2 .

The improvement from using WDM depends on the input load as showed in figure 5. Here, the PLR as a function of the load pr. wavelength is shown for 8 fibre delay lines with the number of wavelengths as the parameter. The PLR increases with the load while WDM leads to a significant improvement. Already, for 2 wavelengths the added flexibility in the buffer is evident from the reduction in the PLR.

\section{Conclusion}

A traffic simulation model has been used to investigate the feasibility and assess the traffic performance of an asynchronous optical packet switch block. A degradation in packet loss ratio is encountered for asynchronous operation which, however, is counteracted by the introduction of WDM. Hereby, a flexibility in the buffer is introduced that makes asynchronous optical packet switches highly competitive from a traffic perspective while eliminating complex optical packet alignment units.

\section{Acknowledgements}

Part of this work has been carried out in the ACTS projects AC043 KEOPS.

\section{References}

11 K. Sato, ECOC'96,vol.2, pp. 27-34, Oslo, Norway, Sept. 1994.

12/ A. Fioretti et al., ECOC'94, vol. 2, pp. 503-509, Florence, Italy, Sept. 1994.

13/ M.G. Hluchyj et al., Journal on Selected Areas in Com., vol, 6, no. 9, pp. 1587-1597, Dec. 1998.

14/ S.L. Danielsen et al., Journal of Light. Technology, vol 15, pp. 219-227, Feb. 1997 